\title{
LA REINVENCIÓN NIETZSCHEANA DE LA ANTIGÜEDAD GRIEGA. EL PERIODO ARCAICO COMO CONTRAIMAGEN DE LA ÉPOCA CLÁSICA GRIEGA
}

Nietzsche's New View of Ancient Greece.

The Archaic Period as Counterimage of the Classic Age

Herbert Frey

Universidad Nacional Autónoma de México

RESUMEN: El artículo presentado intenta demostrar que la interpretación de Nietzsche en torno a la Antigüedad griega representa una novedad y al mismo tiempo una reinvención de los griegos antiguos, articulando como tesis central que los logros más sobresalientes de la cultura griega fueron alcanzados en los siglos VI y v antes de nuestra era, una época que Nietzsche entendía como arcaica o trágica. Al mismo tiempo el artículo subraya que la reinvención nietzscheana de los griegos representa una polémica contra el neohumanismo y la filología clásica de su época. En contra de una visión armónica clásica, nietzsche desarrolla una imagen de Grecia que reasalta los lados oscuros y crueles del mundo antiguo, a través de lo cual pone la visión trágica de los griegos en el centro de su análisis.

Palabras clave: neohumanismo - armonía clásica - visión trágica

Abstract: This article tries to show that Nietzsche's interpretation of Greek antiquity represents a new interpretation and at the same time a reinvention of the ancient Greeks. The central thesis of his interpretation is that the most important achievements of Greek culture were created in the sixth and fifth century before our era. A time which Nietzsche understood as tragic or arcaic. At the same time this article stresses that the reinvention of the Greeks by Nietzsche represents a polemic against neohumanism and the classical philology of his time. Against the armonic vision of classic antiquity Nietzsche develops an image of the Greeks which emphasizes the dark and cruel sides of the Ancient world. Thus he moves the tragic world view of the Greeks to the center of his analysis.

Keywords: Neo-humanism - Classical armony - Tragic vision

Para todos los intérpretes serios de Nietzsche está fuera de duda que la Antigüedad griega y la filosofía de la antigua Grecia constituían una materia fundamental de estudio del filósofo. Como estudiante de Schulpforta, uno de los centros de formación en lenguas clásicas más famosos del reino de Prusia, Nietzsche adquirió profundos conocimientos del griego antiguo y de la Antigüedad griega que, en brevísimo tiempo, le permitieron terminar sus estudios de filología clásica y convertirse en el alumno predilecto de Friedrich Wilhelm Ritschel, quien quizás era el catedrático de filología clásica más reconocido del ámbito germanoparlante. Fue él, también, quien más adelante propuso a la Universidad de Basilea a su dotado alumno como profesor supernumerario de filología antigua. El influyente profesor recomendó a Nietzsche, diciendo que «nunca había tenido 
en mi disciplina a un muchacho que tan pronto y tan joven haya sido tan maduro como este Nietzsche» ${ }^{1}$.

Y, efectivamente, tanto la facultad de Basilea como las autoridades educativas cantonales hicieron caso de esta recomendación. El 13 de febrero de 1869, con apenas 24 años, Nietzsche fue nombrado directamente profesor extraordinario. Con ello se convirtió en uno de los catedráticos más jóvenes que haya tenido el espacio de habla alemana.

Estos hechos son bastante conocidos por todos los investigadores de Nietzsche. Menos conocido, en todo caso, es el hecho de que su entusiasmo por la cultura antigua y la mitología griegas se remonta mucho más atrás, a sus primeros años de juventud. Fue el biógrafo de la infancia y juventud de nuestro filósofo, Hermann Josef Schmidt, quien rastreó el tema de la añoranza de Nietzsche por la antigua Grecia. Ello hizo evidente que el trabajo de Nietzsche con los griegos siempre tuvo el carácter de una acción de salvamento de su propia identidad, frente a las exigencias archipietistas y hostiles a la sensualidad de su casa paterna, que después de la muerte del padre fue convertida por la abuela Erdmuthe, las tías Rosalie y Auguste y la madre Franziska en un bastión de la devoción religiosa.

Frente a la indoctrinación religiosa cotidiana de las mujeres de su casa, en la juventud de Nietzsche solo hubo una figura que se mantuvo apartada de esta conducta piadosa, y ese fue el abuelo David Ernst Öhler, el ilustrado pastor y padre de Franziska, la madre de Nietzsche. En su parroquia rural de Pobles, el abuelo contaba con una extensa biblioteca en la que había muchos clásicos de la Antigüedad griega y romana. Y él mismo fue quien abrió a su nieto esta biblioteca, porque fue el único en la familia que desde muy temprano supo reconocer la genialidad del Nietzsche niño. Devorando literatura clásica en el pabellón del jardín durante sus vacaciones, Nietzsche encontró a través de la biblioteca del abuelo el camino hacia «sus griegos» en el bucólico Pobles. Ellos y solo ellos le ofrecieron desde un principio la imagen y la utopía opuestas a las miserias de su presente cristianoprotestante, hostil a la sensualidad.

Este temprano entusiasmo por lo griego y el impulso anticristiano que surgió de él, han sido ampliamente ignorados por la literatura especializada, pese a que justamente ahí puede encontrarse un antecedente esencial de la interpretación de Nietzsche a la filología clásica, cuya finalidad debería estar al servicio de la vida.

Schmidt, muy probablemente uno de los biógrafos más conocedores y compenetrados con la primera etapa de vida de Nietzsche, sintetizó así su grecofilia:

¿Por qué los griegos pudieron cobrar tal importacia para el niño Nietzsche? Yo supongo [...], que en el niño Nietzsche estaban presentes sentimientos e ideas que podían vincularse de manera óptima con el pensamiento griego; que precisamente desde una 'óptica griega' él pudo experimentar su forma de pensar [...] ya no como inadecuada [...] sino de ahí en adelante como justificada, inclusive como aceptada [...] la comunidad de los creyentes cristianos le estaba vedada al niño Nietzsche [...] así que, con los griegos, este se inventó en parte también a sí mismo, porque trabajó su desarrollo intelectual y emocional con 'material' que encontró entre los griegos ${ }^{2}$.

1. V. Gerhardt, Friedrich Nietzsche, München: Beck, 1995, p. 34

2. H. J. Schmidt, Nietzsche Absconditus oder Spurenlesen bei Nietzsche. Kindheit, Teil 3, Berlin-Aschaffenburg: IBDK, 1991, p. 804 
Todo esto significa que el joven Nietzsche se inventó una cercanía emocional e intelectual específica con «los griegos», que representaban para él la única cultura alternativa asequible frente a la tradición judeocristiana, una tradición que había convertido su vida en un infierno.

No podemos saber con certeza, si «los griegos» fueron tan importantes para Nietzsche porque eran griegos, o porque representaban la única opción a su alcance frente a la religión de sus ancestros. Muy probablemente ambas cuestiones están íntimamente ligadas y merecen ser contestadas afirmativamente ${ }^{3}$.

De modo que cuando Nietzsche planteó en la segunda Consideración intempestiva y en los apuntes a «Nosotros los filólogos» un distanciamiento del enfoque positivista e historicista del estudio de la Antigüedad y de la historia en favor de una interpretación al servicio de la vida, estos impulsos ya se encontraban largamente afincados en su propia historia personal, mucho antes inclusive de que se decidiera a seguir estudios de filología.

¿A qué vienen estas notas introductorias? A que nos parecen necesarias para ubicar en un nuevo contexto todo el conjunto de la invención de los griegos, la filología antigua y la biografía de Nietzsche. De ahí se desprende, que la relación de Nietzsche con los griegos es mucho más compleja de lo que se ha dado a entender hasta ahora en la historia de su recepción. Si bien en la interpretación de Nietzsche desde un principio estuvo claro que su filosofía solo adquirió su propio perfil a través del análisis de la Grecia antigua y la filosofía arcaica, durante mucho tiempo esta relación de Nietzsche con los griegos no tuvo una importancia interpretativa medular como la de los conceptos de la voluntad de poder, el eterno retorno o el superhombre. Y relativamente es desde hace muy poco, que algunos investigadores de Nietzsche consideran a la visión trágica del mundo como central para su interpretación, pese a que esta constituye la bisagra de todo su pensamiento ${ }^{4}$.

Dejando a un lado intentos anteriores, en mi opinión fue Karl Löwith el primero que abordó a fondo la recuperación de la antigüedad griega por parte de Nietzsche, en su innovador estudio La filosofía del eterno retorno de Nietzsche, escrito bajo el impacto del ascenso del nacionalsocialismo. El cuarto capítulo de su libro lleva el sugerente título de «La repetición anticristiana de la Antigüedad en la cúspide de la Modernidad». Si bien él mismo consideró como fallida la pretensión de Nietzsche de reconciliar a la Antigüedad y a la Modernidad entre sí, esta interpretación de todos modos resultó significativa para el propio intento de Löwith de reformular en nuestra época la cosmovisión de los griegos 5 .

Sin contar los escritos de Löwith, la relación de Nietzsche con la antigüedad griega y aunada a ella la filología antigua de su época, apenas empezaron a con-

3. H. Frey, Nietzsche, Eros y Occidente, México: Porrúa, 2001, p. 81.

4. Cf. al respecto P. Köster, Kontroversen um Nietzsche. Untersuchungen zur theologischen Rezeption, Zürich: Theologischer Verlag, 2003, pp. 17-51; W. Ries, Nietzsche für Anfänger. Die Geburt der Tragödie, München: dtv, 1999; W. Ries, «Tragische Welterfahrung contra wissenschaftliche Weltbetrachtung. Nietzsches Beitrag zum Dilemma der Modernität», en R. Reschke (ed.), Nietzsche, Radikalaufklärer oder radikaler Gegenaufklärer?, Berlin: Akademieverlag, 2004, pp. 103-109.

5. K. Löwith, Nietzsches Philosophie der ewigen Wiederkehr des Gleichen, Hamburg: Felix Meiner, 1986 (1935); cf. también «Nietzsches Versuch zur Wiedergewinnung der Welt», en Gott, Mensch und Welt-G. B. Vico - Paul Valéry, Stuttgart: Metzler, 1986, p. 117. 
tar con un nuevo, pero después creciente y sostenido interés a partir de los años ochenta del siglo pasado. Los trabajos citados a pie de página, dejan ver que la relación de Nietzsche con la cultura antigua y la filosofía griega se desplaza cada vez más hacia el centro de la investigación nietzscheana, porque de ahí en adelante se convierte en un tema toral del debate con nuestro filósofo ${ }^{6}$.

Solo en tiempos muy recientes se ha vuelto a tomar en cuenta que la revaloración de la Antigüedad griega hecha por Nietzsche permeó de manera fundamental todos sus escritos, desde sus primeros ensayos sobre fatum e historia hasta sus obras tardías como La genealogía de la moral, El crepúsculo de los ídolos, El Anticristo y los apuntes de finales de los años ochenta.

En la interpretación de Nietzsche, la antigüedad griega siempre aparece como un contramito, como una imagen opuesta a la Modernidad creyente en el progreso, a la teleología de la tradición judeo-cristiana, sugiriendo que lo que fue alguna vez, así fuese aquella relación natural solo imaginada con la physis y el cosmos, podía ser posible otra vez.

Antes del giro socrático, la religión, la sociedad y la polis griegas constituian un ideal de la existencia social, de la relación sensual y erótica con el mundo, que las religiones monoteístas destruyeron al despojar al cosmos de su divinidad, y devaluar al mismo tiempo con ello la sensualidad y corporalidad humanas.

En su rehabilitación de la ética y la cosmovisión de la antigua Grecia, Nietzsche se ubicaba sin embargo más sólidamente dentro de una tradición de autocrítica europea a la Modernindad, de lo que pudiera parecer a primera vista. Es un hecho poco discutible, que desde el Renacimiento la recurrencia de una élite de mentes europeas a las imágenes de la Antigüedad griega y romana, siempre tuvo tendencialmente un componente crítico, que más implícita que explícitamente se orientaba contra la tradición cristiana. Aunque de manera diferente, esto es aplicable tanto a Maquiavelo como a Montaigne y, a la par de Panajotis Kondylis,

6. Es evidente que aquí no se puede hacer una reseña de la investigación más reciente sobre la imagen griega de Nietzsche. E. Müller proporcionó una panorámica sobre el último estado de esta investigación en «Neuerscheinungen zu Nietzsches Bild der Antike»: Nietzsche-Studien 31 (2002), 350-362. Trabajos importantes que han tematizado la relación de Nietzsche con Grecia y con la filosofía griega son: H. Ottmann, Philosophie und Politik bei Nietzsche, Berlin: W. de Gruyter, 1987 (21999); T. Borsche, «Nietzsches Erfindung der Vorsokratiker», en J. Simon (ed.), Nietzsche und die philosophische Tradition, vol. 1, Frankfurt a. M.: P. Lang, 1985, pp. 62-88; P. D’Iorio, «L'image des philosophes préplatoniciens chez le jeune Nietzsche», en T. Borsche (ed.), Centaurengeburten, Wissenschaft, Kunst und Philosophie beim jungen Nietzsche, Berlin: W. de Gruyter, 1994, pp. 382-417; H. Cancik, Nietzsches Antike, Vorlesung, Weimar, 1995. Sobre la interpretación heracliteana de Nietzsche: G. Wohlfahrt, "Also sprach Herakleitos», Fragment B 52 und Nietzsches Heraklitinterpretation, Herder: Freiburg i. B., 1991; Íd., Das spielende Kind. Nietzsche: Postvorsokratiker - Vorpostmoderner, Essen: Vulkan, 1999. Como para olvidar: V. Tejeira, Nietzsche and Greek Thought, Dordrecht: Springer, 1987. Más bien decepcionante: P. Bishop, Nietzsche and Antiquity. His Reaction and Response to the Classical Tradition, New York: Camden House, 2004. Un nivel de reflexión mucho más sutil, que de aquí en adelante no puede ser soslayado en la interpretación de la Antigüedad que hace Nietzsche, muestran los estudios de J. L. Porter, The Invention of Dionysus. An Essay on the Birth of Tragedy, Stanford UP, 2000; pero especialmente: Nietzsche and the Philology of Future, Stanford UP, 2000. Por último deben mencionarse dos estudios recientemente publicados, que se complementan entre sí. La tesis doctoral de E. Müller, en la Universidad de Greifswald, publicada bajo el título Die Griechen im Denken Nietzsches, Berlin: W. de Gruyter, 2005; y C. Benne, Nietzsche und die historisch-kritische Philologie, Berlin: W. de Gruyter, 2005. 
se podría definir a toda la Ilustración francesa como un movimiento de rehabilitación de la sensualidad?.

Debido a sus condiciones históricas específicas, la situación en Alemania era mucho más extrema que en otros países católicos de Europa. El protestantismo, en todas sus variantes, se había evidenciado todavía más hostil hacia la sensualidad que el catolicismo, y todos los intentos revolucionarios por establecer libertades ciudadanas habían sido sofocados en su germen. En este contexto es en el que debe entenderse la creación de una imagen de la antigüedad griega; una construcción, una invención que, en todo caso, no estaba consciente de tal carácter. Dada la situación histórica de Alemania, resulta comprensible que, a partir del siglo XVIII, las mentes más lúcidas de la escena literaria se sumaran a un concepto glorioso de la antigüedad griega, el cual, aunque de manera encubierta, daba expresión a sus propias concepciones políticas. Winckelmann acuñó la expresión de «la noble sencillez y la serena grandeza» y, con ella, determinó por decenios el clasicismo griego en el espacio de habla alemana. La nostalgia hacia esta imagen caracterizó a Lessing, Schiller y Goethe, y dio justificación a las aspiraciones republicanas de Hölderlin. La construcción de una antigüedad griega que, a la par, era siempre gloriosa, legitimaba la oposición a una cultura alemana dominada por el protestantismo pietista y abría una posibilidad de protesta aceptada contra la arbitrariedad del Estado y el tutelaje cultural. En todo caso, esta imagen de Grecia debía mantenerse exenta del ideal aristotélico de una comunidad ciudadana comprometida con el objetivo de ejercer las funciones del Estado ${ }^{8}$.

También Herder se entusiasmó por los griegos, sin desconocer empero los rasgos oscuros, las guerras y las invasiones, que les eran tan propios como sus excepcionales logros culturales. En el neohumanismo de Wilhelm von Humboldt, empero, Grecia fue estilizada estéticamente y, por último, sujeta a fines pedagógicos9. En la ficción de los neohumanistas, Grecia se transformó en un lugar donde predominaban la belleza, el valor y la sabiduría. Y aunque esta imagen no era capaz de soportar un análisis histórico, sí surtió efecto en aquella coyuntura histórica de Alemania.

Si bien con la reforma escolar prusiana de principios del siglo XIX el latín y el griego antiguo se convirtieron en materias prioritarias del Gymnasium o enseñanza media en Prusia, con la institucionalización de la filología antigua también se le quitó al tema de la Antigüedad su aguijón crítico $^{10}$.

El estudio de la Antigüedad clásica degeneró en simple filología, la cual neutralizó el efecto liberador del clasicismo griego y borró el antagonismo entre la cosmovisión pagana y la visión cristiana del mundo.

Fue la pérdida de esta función crítica del trabajo con la Hélade, la pérdida del entusiasmo como precondición para el estudio de la filosofía antigua y la utilización de este conocimiento en beneficio de la vida concreta, lo que Nietzsche

7. P. Kondylis, Die Aufklärung im Rahmen des neuzeitlichen Rationalismus, München: dtv, 1986.

8. G. Bollenbeck, Bildung und Kultur, Glanz und Elend eines deutschen Deutungsmusters, Frankfurt a. M.: Suhrkamp, 1996.

9. Zur Rezeption der griechischen Antike im geistigen Leben Deutschlands (ę?); cf. también V. Riedel, Antikerezeption in der deutschen Literatur. Von Renaissance-Humanismus bis zur Gegenwart, Suttgart: Metzler, 2000, pp. 132-211.

10. F. K. Ringer, Die Gelehrten. Der Niedergang der deutschen Mandarine, München: dtv/Klett Cotta, 1987, pp. 32-36. 
deploró desde el inicio de su carrera académica. En sus apuntes de 1875 para «Nosotros los filólogos», Nietzsche formuló sus objeciones contra la filología clásica de su época de la siguiente manera:

¡Formación clásica! Vaya, si por lo menos hubiese en ella tanto paganismo como el que Goethe encontró y glorificó en Winckelmann - que ni siquiera era demasiado. Pero ahora agregarle, o mezclarle, todo ese cristianismo falaz de nuestra época esto ya es demasiado para mí y necesito desahogarme expresando mi repugnancia hacia ello. En lo que concierne a esta «formación clásica», se cree literalmente en magia; precisamente aquellos que más cercanía tienen con la Antigüedad, es decir los filólogos, tendrían también que tener más de esta formación. ¿Pero qué hay de clásico en ellos? ${ }^{11}$.

Frente a esta mezcla de Antigüedad griega y cosmovisión cristiana, Nietzsche tuvo que desarrollar una imagen diferente, nueva, de los griegos, que también tomara en cuenta el lado oscuro y terrible de la existencia. De ahí que Nietzsche recurriera a los presocráticos, en cuya filosofía veía reflejado el aspecto trágico de la existencia humana; de ahí su reinterpretación de la tragedia griega, con la cual quería conferir nueva vida al mito trágico.

Nietzsche está convencido de haber redescubierto la filosofía griega más antigua. Sin embargo está consciente de que lo nuevo en este descubrimiento se debe a la perspectiva de su tiempo y de su situación, porque cada situación nueva requiere de su propio pasado. Junto con el ideal del filósofo, lo que él descubrió ahí es, ante todo, el modelo de una filosofía del futuro. Esta le parece un remedio posible y necesario para la miseria espiritual de su época ${ }^{12}$.

El ataque de Nietzsche al ideal clásico de la humanidad y su idea, como filósofo y filólogo al mismo tiempo, de someter a la filosofía a las exigencias de la vida y del futuro, llevó a malentendidos que, hasta ahora, el gremio de los filólogos no ha logrado superar ${ }^{13}$.

Sin embargo, la crítica de Nietzsche estaba dirigida sobre todo contra el positivismo de la filología antigua de su época, no tanto contra sus padres fundadores como Winckelmann y Wolf. Al contrario, justamente lo que quería revivir era su entusiasmo por la antigua Grecia. Solo que, para Nietzsche, su ideal no era la Grecia de Sócrates, Platón y Pericles, sino otra más antigua, más arcaica, la de los presocráticos, cuya filosofía que él llamaba trágica llevó al centro de su interpretación. Su objetivo era el de la renovación de la cultura griega, y la interpretación de esta no pretendía dar la despedida a la humanidad clásica, sino renovarla.

Si Nietzsche tuvo éxito o no en preservar la humanidad clásica, ya es otra cuestión. Pero en contra de todas las barbarizaciones que han operado a lo largo de la historia, tiene primero que aparecer en el horizonte un Nietzsche, quien puede ser

11. KSA VIII 75: 5 [138].

12. T. Borsche, «Nietzsches Erfindung der Vorsokratiker», en J. Simon, Nietzsche und die philosophische Tradition, vol. 1, Würzburg: Königshausen \& Neumann, 1985, p. 77.

13. Cf. al respecto P. Latacz, «Fruchtbares Ärgernis: Nietzsches Geburt der Tragödie und die gräzistische Tragödienforschung», en Nietzsche in Basel, Basel: Basler Universitätsreden, 1998, pp. 26-31. 
interpretado como un aún-clásico, que como un ya-no-clásico como un anticlásico clásico $^{14}$.

La interpretación de Henning Ottmann, «Nietzsche, el anticlásico clásico», será la que guiará de aquí en adelante nuestra caracterización del Nietzsche de los primeros tiempos.

Ya desde el principio de la polémica con la filología clásica, Nietzsche era consciente de la crisis por la que atravesaba su especialidad. Creía, que esta solo era salvable mediante una vinculación con la filosofía y la estética contemporáneas. Era precisamente el filólogo el que debía apegarse a la filosofía, si pretendía todavía defender el carácter clásico, es decir la ejemplaridad persistente de la Antigüedad; porque se trataba de un juicio que tenía que fundamentarse y defenderse filosóficamente. Frente a la historización y, con ella, la validación comparativa de los textos antiguos, Nietzsche insiste en su validez atemporal. Para quien la acepta, estos textos tienen el potencial de modificar y determinar la vida. Según Nietzsche, el método histórico-crítico de la filología clásica padecía de una autosobrevaloración, dado que olvidaba que todo trabajo histórico siempre está al servicio de poderes e intereses ahistóricos y, por ende, no es factible como ciencia «pura» ${ }^{15}$.

No se trata de una condena al método filológico o a la visión histórica del mundo, sino de un fundamento con energía vital para el historismo. Nietzsche quiere retornar al futuro: piensa que la fascinación estética, que es la única que puede preservar el valor de la Antigüedad en el presente, se ha perdido ${ }^{16}$.

Era mejor que la escuela crítica de la filología antigua se orientase con un renovado entusiasmo hacia la estética contemporánea, que hacia una historia universal indiferente. Si Nietzsche quería renovar la filología antigua, tenía que desarrollar una imagen diferente de la antigüedad griega; una imagen que fuera contraria a la de la filología clásica de Winckelmann y Wolf, pero también a la de Goethe. De lo que se trataba, era de colocar el estudio de la filología nuevamente al servicio de la vida y hacer a un lado ese ideal humano clásico que, con su creencia en el progreso y su reconciliación con el cristianismo, se había vuelto intolerable para Nietzsche.

De ahí la invención por parte de nuestro filósofo de una Antigüedad diferente, nueva, que tuvo su cúspide en un periodo mucho anterior a la aparición de Pericles, Sócrates, Platón, Sófocles y Eurípides. Nietzsche habla del siglo vi antes de Cristo. Su interés científico, así como sus esperanzas pedagógicas y políticas están depositados en una «Antigüedad más antigua», en una época arcaica que se diferencia claramente del periodo helénico clásico.

«Tenemos que hacer una distinción dentro de la propia Antigüedad» ${ }^{17}$, es decir, distinguir al helenismo antiguo del helenismo tardío; a los filósofos más antiguos, a los viejos líricos y a Homero, pero también a Esquilo, a quien Nietzsche reclama para la etapa temprana de Grecia. «Se trata de liberar al siglo VI (a.C.) de

14. H. Ottmann, Philosophie und Politik bei Nietzsche, Berlin: W. de Gruyter, 1999, pp. 43-44.

15. HL 1, KSA I 257.

16. C. Benne, Nietzsche und die historisch-kritische Philologie, Berlin: W. de Gruyter, 2005, p. 289.

17. KSA VIII 53: 5[47]. 
su tumba» ${ }^{18}$. La época ejemplar, no es la de la Atenas del siglo v con Fidias, Sócrates, la tragedia, la democracia y el nomos como lo habían enfatizado los filólogos clásicos. El objetivo de Nietzsche es resucitar de la muerte a la llamada época «arcaica». Los elementos más distintivos de esta época son el florecimiento de la polis, la rivalidad de las ciudades-Estado, el surgimiento de la filosofía griega, desde Tales de Mileto (624-546 a.C.) hasta Anaxágoras (500-428 a.C.) y Empédocles. Pero Nietzsche no denominaba a esta época como la «filosófica» o presocrática, sino como la «trágica». Y con ello creó el significado especial de una época, que en la filología antigua convencional tenía una relevancia mucho menor.

Delimitar una época, significa hacer un corte, establecer una «cesura». Con ello se desvía la atención y determinados personajes o grupos de personas son reunidos, otros separados. La decisión de Nietzsche de dar por terminado el apogeo de la cultura de la polis ya antes de 560 a.C., separa por un amplio intervalo el florecimiento de la cultura clásica, es decir de la cultura ateniense del siglo $\mathrm{v}$, de aquel periodo arcaico que para él representaba un punto culminante de la cultura griega.

Esta revaloración tuvo consecuencias sorprendentes. Y es que el objetivo de Nietzsche era romper el encanto de la Atenas clásica de Pericles y Platón, y estremecer con ello los cimientos del viejo humanismo liberal, la fatuidad de la visión educativa burguesa. De ahí el demoledor rechazo a las invenciones de Nietzsche por parte del gremio de los filólogos clásicos, para quienes su antihumanismo era un horror. Ya en el invierno de 1869-1870, Nietzsche resumió sus ideas sobre el declive de la etapa arcaica.

Después de las guerras con los persas, el helenismo tenía que derrumbarse. Su elemento fundamental, el fervientemente amado Estado pequeño, que se medía en la lucha con los otros, fue ampliamente superado en estas guerras, sobre todo desde un punto de vista ético. La cúspide de la filosofía con los eleatas y Empédocles. La voluntad del heleno se quiebra en la guerra con los persas: el intelecto [la fría racionalidad científica] se torna extravagante e insolente ${ }^{19}$.

Junto con Jakob Burckhardt, su gran colega de Basilea, Nietzsche está convencido de que la competencia era un elemento constitutivo de la cultura arcaica. La idea de que el agon tenía una importancia fundamental para el carácter del pueblo griego, fue recogida por Nietzsche y generalizada en el prototipo del hombre «agonal». En la época arcaica es donde más abundantemente se encuentra representado este modelo. Para Nietzsche, el Estado arcaico genera energías formidables, que luego, de manera secundaria, hacen surgir logros intelectuales.

Debemos desear, que la vida conserve su carácter violento, que las energías y las fuerzas indómitas sean convocadas. El dictamen sobre el valor de la existencia, es el resultado máximo de la tensión que prevalece dentro del $\operatorname{caos}^{20}$.

Pero también la rivalidad de los helenos entre sí fomentaba la cultura; los griegos cultivaban sus rivalidades. Nietzsche ve por todas partes «un trasfondo

18. KSA VII 212: 7[191].

19. KSA VII 46: 2[6].

20. KSA VIII 93: 5[188]. 
malvado y terrible» ${ }^{21}$. Este proporcionaba las energías para el surgimiento de la cultura, para la virtud, y hacía de esta un logro necesario. La cultura no es una decoración arbitraria y externa, sino un elemento vital. Según nos enseña la cultura griega arcaica, el Estado rapaz es imprescindible para el Estado cultural. El Estado de la cultura, empero, es el sentido, la meta, la legitimación del Estado rapaz.

Nietzsche se da cuenta de que su nueva interpretación de la antigüedad griega se dirige contra la ciencia positivista de la filología clásica en su conjunto, frente a cuya invención de la Antigüedad clásica él presenta un contraproyecto. Pero Nietzsche sabe que su época arcaica vive a partir de una invención de la que él está consciente, en tanto que la filología clásica cree investigar verdades que son intemporales. Con ello, Nietzsche alcanzó un punto de reflexión que era tabú para las ciencias positivistas tradicionales. Apenas en el legado de los años ochenta, aparece en Nietzsche una explicación de lo que ya sostenían implícitamente en los años setenta sus escritos sobre la Antigüedad griega.

Frente al positivismo, que ante los fenómenos se queda en que 'solo hay hechos', yo diría: no, justamente lo que no hay son hechos, solo interpretaciones. No podemos corroborar ningún hecho... Todo es subjetivo, dicen ustedes: pero ya esto es una interpretación. El sujeto no es algo dado, sino algo inventado al respecto... el mundo no tiene un sentido en sí, sino innumerables perspectivas de sentido ${ }^{22}$.

Otra cita del legado, esta de los años 1885-1886, endurece la visión de Nietzsche sobre el carácter interpretativo:

Que el valor del mundo radica en nuestras intepretaciones... que las interpretaciones hasta ahora existentes son apreciaciones perspectivistas, gracias a las cuales nos sustentamos en la vida, es decir en la voluntad de poder, para el incremento del poder; que cada elevación del hombre trae consigo la superación de interpretaciones más estrechas; que cada fortalecimiento y cada ampliación de poder alcanzados abren nuevas perspectivas... todo esto está presente en mis escritos ${ }^{23}$.

La relativización del carácter verídico de toda comprensión histórica, y con ello implícitamente la destrucción de toda posibilidad de conocimiento objetivo, volvió a Nietzsche insoportable para el gremio científico del siglo xIX. Con este planteamiento, nuestro filósofo amenazaba abiertamente los conceptos científicos de los historiadores, destruyendo con ello la creencia en una verdad única y sustancial.

Hay tantas verdades sobre el pasado, como hay perspectivas individuales. El estudio de la Antigüedad solo podía justificarse, si lograba transformarse de vuelta en un vehículo para alcanzar una nueva meta ${ }^{24}$. Para Nietzsche, el estudio de la Antigüedad griega debía estar al servicio del presente y de la vida, si pretendía afirmar su derecho a existir.

Lo que fue, ya no es, y existe como imago solo por el hecho de que se le narra actualmente. El pasado como historia es siempre un modus del presente... Como

21. KSA VIII 19: 3[17].

22. KSA XII 315: $7[60]$.

23. KSA XII 114: 2[108].

24. Cf. al respecto H. White, Metahistory, Frankfurt a. M.: Fischer, 1991, p. 427. 
narración, toda descripción del pasado es también siempre una construcción, por más que se apegue a los hechos empíricos ${ }^{25}$.

Esta es, empero, la justificación de Nietzsche para su nueva interpretación de la antigüedad griega. Si cada época tiene que rescribir su historia, entonces se justifica el proyecto de Nietzsche, que contrapone a la interpretación de los clásicos su propia interpretación del pasado griego.

Ahora que si en concreto queremos esclarecer algunos momentos de la interpretación nietzscheana de la Grecia antigua, debido al limitado espacio de este artículo tendremos que circunscribirnos a la primera etapa creativa de Nietzsche, a pesar de que estamos convencidos de que la visión trágica del mundo es un concepto que persiste en sus escritos hasta su obra tardía.

En la primera fase de su creación intelectual, que abarca de 1869 a 1876 y coincide fundamentalmente con su actividad docente en Basilea, Nietzsche se concibe a sí mismo como un "médico de la cultura» ${ }^{26}$, como un renovador radical de lo helénico y como el creador de una mitología germanogreca, cuya esperanza se fundaba en la metafísica de Schopenhauer y la música de Wagner. Durante la primera mitad de los años setenta, ya fuera en "El Estado griego" (1872), en «La competencia de Homero», en «La filosofía en la era trágica de los griegos» (1873) y, no por último, en su escrito más conocido El nacimiento de la tragedia a partir del espíritu de la música (1872), las reflexiones de Nietzsche giraban en torno de cómo las enseñanzas griegas podían ser aprovechadas en el presente.

Frente al Estado imperial de su tiempo, Nietzsche dibujó la imagen de un Estado que, como en los primera fase de la Antigüedad, estuviera subordinado a la cultura. Como remedio contra la visión optimismta del progreso ilimitado, predicó el renacimiento del mito trágico, que veía prefigurado por una parte en el mundo de los presocráticos y, por otra, en la tragedia ática.

Lo que Nietzsche encontraba en la visión presocrática del mundo, según su interpretación, era una concepción estética de la existencia, que única y solamente encontraba su justificación a través del arte. La cultura era el objetivo de Nietzsche y esta no debía excluir a la humanidad clásica, sino renovarla. Aun cuando Nietzsche valoraba a Winckelmann, Wieland y Goethe, le parecía muy superficial contemplar a los griegos únicamente desde la óptica de «almas bellas» y creadores de obras de arte llenas de armonía. Los clásicos habían glorificado a los griegos, sin tomar en cuenta su lado oscuro y su crueldad.

En una carta a su amigo Erwin Rhode, fechada el 16 de julio de 1872 , Nietzsche destaca el lado oscuro del mundo helénico. "Que un tremendo y salvaje forcejeo lo precede, surgido de la más oscura barbarie y crueldad, y que Homero queda como vencedor al final de este largo y desolado periodo, esta es una de mis convicciones más firmes» ${ }^{27}$. En El nacimiento de la tragedia, Nietzsche expone su interpretación alternativa de la antigüedad griega de la siguiente manera:

25. R. Burger, Im Namen der Geschichte. Vom Mi brauch historischer Vernunft, Hannover: Klampen, 2007, p. 116.

26. KSA VII $545: 23[15]$.

27. KSB IV 23. 
El griego conocía y sentía los horrores y espantos de la existencia: para siquiera poder vivir, tuvo que anteponer a ellos la brillante imagen de los dioses del Olimpo. Aquella enorme desconfianza frente a las fuerzas titánicas de la naturaleza, [...] fue encubierta y sustraída a la mirada por los griegos mediante ese mundo artístico intermedio del Olimpo. Para poder vivir, los griegos tuvieron la profunda necesidad de crear estos dioses ${ }^{28}$.

Si bien los escritos de Nietzsche durante el periodo de Basilea interpretan de manera original y filológicamente cuestionable la Antigüedad griega, su meta interpretativa era una crítica del presente, al cual el filósofo colocaba frente al espejo de una cultura a la que consideraba ejemplar. «El Estado debe preparar la producción y la comprensión del genio ${ }^{29}$, sostenía Nietzsche. Para esto se le requiere y con ello se justifica.

Fue Jakob Burckhardt, su colega ilustre en Basilea, quien definió a los griegos como hombres heróicos y agonales. Tanto para Nietzsche como para Burckhardt la lucha, Agon, y la disputa, Eris, serían las parteras de la cultura griega. Nietzsche hizo suyo el ideal de esta cultura y reconoció lo que le era porpio: el desprecio por el trabajo común y el alto aprecio por la lucha y la disputa.

También en «La competencia de Homero», la imagen que Nietzsche traza de los griegos difiere de la de los clásicos alemanes. La crueldad, la envidia, «el gusto por el aniquilamiento propio de tigres ${ }^{30}$ y la disputa eran parte de su cultura, escribe en este pequeño tratado. Y, a pesar de ello, los griegos no eran inhumanos, sino «los hombres más humanos de la Época Antigua» ${ }^{31}$. Pero su humanidad guardaba con la naturaleza una relación diferente a la de los tiempos modernos. Ellos reconocían a la naturaleza también en sus rasgos inhumanos, en el odio y la envidia, la ambición y la crueldad. No negaron estos aspectos, sino que los reconocieron y los domeñaron a través del Agon. Entre los griegos, el Agon no constituía un fin en sí mismo; su móvil no era la ambición egoista de la Época Moderna; sus objetivos eran la gloria de la ciudad, la educación, la cultura ${ }^{32}$.

$\mathrm{Al}$ querer regresar a los tiempos iniciales de la cultura griega, Nietzsche quería también regresar a los presocráticos. Esto se debía a su ruptura con Sócrates y a su distanciamiento con la metafísica de Platón, pero su motivo más importante y oculto radicaba en su anticristianismo, que en esa época todavía no era abiertamente manifiesto.

Nietzsche glorificó a los presocráticos como «filósofos en la era trágica de los griegos», como solitarios y orgullosos buscadores de la verdad, como filósofos de una cultura floreciente y no enferma; en fin, como tipos puros en contraposición con el «carácter mixto» al que dio inicio la filosofía heráclito-pitagóricosocrática de Platón ${ }^{33}$. Seguir su filosofía significaba para Nietzsche una travesía por «el puente invisible tendido de genio a genio», una especie de camino real a través de la historia mundial que, en cierto modo, encuentra su abreviatura en los primeros filósofos.

28. GT $\$ 3$, KSA I 35-36.

29. KSA VII 142: 7[23].

30. HW, KSA I 783.

31. Ibid.

32. HW, KSA I 789.

33. PHG, KSA I 805-810. 
En muchos aspectos, para la propia postura de Nietzsche el mundo de los presocráticos era paradigmático. En él había una mezcla de mitología y afán de ciencia, que coincidía con su propia ambivalencia; con su inicial búsqueda del mito y su posterior giro hacia la ciencia. Aquí, como en Empédocles y Demócrito, había el intento de una filosofía de la naturaleza antiteleológica; aquí había tragedia, como en Empédocles y Anaximandro; materialismo, como en Demócrito; y aquí, junto con antropomorfismos éticos y lógicos, había también estéticos: el nous de Anaxágoras era un artista; el mundo para Anaxágoras y Heráclito, «un juego» ${ }^{34}$.

De todos ellos fue Heráclito quien ejerció una mayor influencia sobre Nietzsche, cuyas primeras concepciones se vieron marcadas por un triple heraclitismo: como filosofía de la lucha cósmica de las fuerzas, como estética del juego cósmico; y como una filosofia radical de la naturaleza y la moral que, junto con la posteriormente llamada «inocencia del devenir», se postuló contra la metafísica griega tardía y la metafísica cristiana y, en general, contra toda moral imperativista.

Heráclito, por motivos diversos, se convirtió para Nietzsche en el más importante de los presocráticos. Ahí estaban, por un lado, la fascinación por su persona, en su solitaria y orgullosa búsqueda de la verdad, y su aristocratismo, que no esperaba la comprensión de las masas. «Uno me vale más que diez mil, si es el más capaz» ${ }^{35}$, había sentenciado Heráclito. Y, por otro lado, estaba ahí también el vínculo entre cultura agonal y polemos. Heráclito transfirió el agon al «engranaje del cosmos» ${ }^{36}$.

Nietzsche compartía con Heráclito la interpretación de que la guerra es «el origen de todas las cosas», y el cosmos un devenir y no un ser. El mundo es justo en su génesis y en su extinción, «la lucha de lo múltiple en sí, es la única justicia ${ }^{37}$.

«El tiempo, Aion», dice Heráclito, «es un niño, un niño ante un juego de tablero; un niño ocupa el trono $»^{38}$. De manera correspondiente, Nietzsche escribe que el universo es el «juego» de un niño, «un nacer y fenecer, un construir y destruir sin atribución moral alguna, en inalterable inocencia eterna ${ }^{39}$. Heráclito se había anticipado a Nietzsche: ningún ser eterno, ninguna teleología que permitiese reproducir el ciclo de origen, pecado y redención; ninguna ética que proclamara imperativos en nombre del sujeto moderno, de su libertad y su autonomía; en lugar de todo ello, otra vez el antiguo terreno de la physis, despojado de la moral y de la lógica, y justificado estéticamente como lucha de fuerzas.

El heraclitismo de Nietzsche, que concebía al cosmos como un juego, era parte de una metafísica que, en su totalidad, era una metafísica estética. Sus conceptos básicos o, mejor dicho, sus mitologemas, los había derivado de una interpretación de la cultura helénica, de la mitología de los dioses Apolo y Dioniso, así como de la reconstrucción de la tragedia griega. Esta, según Nietzsche, habría surgido de la unión de lo apolíneo con lo dionisiaco. Pero su intención

34. PHG, KSA I 870-871.

35. Heráclito, Fragmento B 49.

36. PHG, KSA I 825 .

37. PHG, KSA I 827.

38. Heráclito, fragmento B 52.

39. PHG, KSA I 830. 
básica no era tanto una reconstrucción histórica, sino más bien un llamado a su época a retornar a una concepción trágica de la vida.

En la esperanza que Nietzsche había depositado en el renacimiento del mito trágico, habría de cumplirse su gran aspiración: la recuperación de la alta cultura. Ello presuponía el reconocimiento de lo trágico, pero ofrecía un consuelo: el arte. Según el «Evangelio del arte» de Nietzsche, la existencia y el mundo solo se justifican como fenómeno estético ${ }^{40}$. El mundo es sufrimiento y horror, así lo enseñaron los griegos y después Schopenhauer; pero ya en su escrito de la tragedia Nietzsche busca una salida que difiere de la de este último. En lugar de la supresión de la voluntad de vivir, Nietzsche va en búsqueda de un «pesimismo de la fortaleza» y una afirmación pesimista de la vida ${ }^{41}$.

La voluntad en «la eterna plenitud de su placer» era representada por Dioniso: símbolo de una inquebrantable alegría de vivir, pese a todo el sufrimiento. En este sentido, Nietzsche redescubrió al dios Dioniso desde la tradición del romanticismo; el dios de la fecundidad vegetativa, que descuartizado se vuelve a parir a sí mismo. El dios rodeado de silenos y sátiros, bacantes y ménades, celebrado en los misterios y las dionisias, que hasta hoy en día es asociado con el desenfreno sexual y las fiestas orgiásticas. Y por el otro lado Apolo, el dios de la mesura y la circunspección, el dios del Oráculo de Delfos, mentor de las musas y amo de las ciencias. Y del contraste y la unión entre ambos, Nietzsche vio surgir el mito trágico y la elevada cultura griega.

El sueño y la embriaguez, así como el arte que surgió de ambos, fueron para Nietzsche la respuesta que los griegos dieron a la experiencia de un mundo caracterizado por el sufrimiento y el horror. En un proyecto de prólogo a El nacimiento de la tragedia, Nietzsche dice que los griegos le habrían enseñado que «no existe una superficie realmente bella, sin un fondo espantoso ${ }^{42}$. El arte daría expresión plena al carácter trágico de la existencia, sin mitigarlo ni disimularlo. Así, cuando en su muy posterior prefacio a El nacimiento de la tragedia, Nietzsche afirma que ya entonces era un tácito anticristo, inmoralista e intercesor artístico de la vida, sin duda esto — cum grano salis - era verdad ${ }^{43}$.

La narrativa de Nietzsche sobre la tragedia tenía como objetivo la renovación del mito trágico. Era el intento de recuperar una inmediatez cercana a la naturaleza, que descansaba segura en sí misma, vigorosa y generadora de cultura, en oposición al «socratismo» de su época, creyente en el progreso, y contra el desbordamiento de lo histórico y la trivialización de la cultura. Nietzsche estaba convencido de que sin mitos, «toda cultura pierde su sana fuerza creativa natural: solo un horizonte rodeado de mitos logra encerrar todo un movimiento cultural, dándole unidad» ${ }^{44}$. Lo que el mito debía reanimar era un carácter trágico opuesto al espíritu optimista de la época, y que cifraba sus esperanzas en un placer trágico, que era meramente estético.

Haber puesto al descubierto el trasfondo, la base de la cultura griega como un mundo dominado por el horror y el implacable afán de destrucción, fue un

40. GT $\$ 29$, KSA I 152.

41. KSA XIII 228: 14[25].

42. KSA VII 130: 6[3]

43. GT, KSA I 17.

44. GT $\$ 23$, KSA I 145. 
escándalo que Nietzsche desató con la introducción de su dios Dioniso en el gremio filológico. Como verdugo del gremio, Ulrich von Wilamowitz-Moellendorf, entonces de 25 años y que más tarde se convertiría en uno de los filólogos más destacados de Alemania, sometió a El nacimiento de la tragedia de Nietzsche a una demoledora crítica filológica, que destruyó para siempre su reputación científica como filólogo. Wilamovitz no hizo esto únicamente por rigor científico, sino porque percibió al escrito de Nietzsche como una afrenta, un verdadero atentado contra los conceptos de lo bueno, lo verídico y lo bello. "Al derribar el pilar de un templo de erudición que se había vuelto frágil, Nietzsche cometió un sacrilegio que los sumos sacerdotes del gremio filológico jamás le pudieron perdonar ${ }^{45}$.

En los años posteriores, Nietzsche ya no atribuyó al mito el efecto salvador de una contracultura, pero se mantuvo fiel a su amor por la Antigüedad griega. La Antigüedad trágica, dionisiaca, versus la Modernidad cristiana; esta era la dicotomía que, hasta el final, podrían haber llevado por título y como última voluntad sus escritos. Bajo el encabezado «Dioniso contra el Crucificado», en el legado de 1888 aparece el siguiente resumen de Nietzsche:

Dioniso contra el Crucificado: ahí tenéis el contraste. No se trata de una diferencia en cuanto al martirio - es solo que el mismo tiene otro sentido. La vida misma, su perenne fecundidad y eterno retorno produce el sufrimiento, la destrucción, la voluntad de aniquilamiento ... en el otro caso el sufrimiento, «el Crucificado como el inocente», sirve como objeción contra esta misma vida, como fórmula de su enjuiciamiento.

Uno adivina: el problema es el del sentido del sufrimiento; un sentido cristiano o uno trágico... En el primer caso, es el camino hacia un estado de bienaventuranza; en el segundo, la existencia ya se considera suficientemente bienaventurada como para poder justificar una enorme cantidad adicional de dolor ${ }^{46}$.

Nietzsche reacciona contra la Modernidad cristiana creyente en el progreso, invocando a la sabiduría griega, y esta es su fórmula para la rehabilitación de la sensualidad y la recuperación del mundo.

45. W. Lange, «Tod ist bei Göttern immer nur ein Vorurteil. Zum Komplex des Mythos bei Nietzsche», en K. M. Bohrer, Mythos und Moderne, Frankfurt a. M.: Suhrkamp, 1983, p. 115; cf. también K. Gründer, Der Streit um Nietzsches Geburt der Tragödie, Hildesheim: G. Olms, 1969, p. 135. 46. KSA XIII 266: 14[89]. 